\title{
Spectrophotometric properties of Moon's and Mars's surfaces exploration by shadow mechanism
}

\author{
Alexandr Morozhenko, Anatolij Vidmachenko and Nadiia Kostogryz
}

Main Astronomical Observatory of NAS of Ukraine, email: avshulga@mail.ru

\begin{abstract}
Typically, to analyze the data of the phase dependence of brightness atmosphereless celestial bodies one use some modification of the shadow mechanism involving the coherent mechanism. There are several modification of B.Hapke [2] model divided into two groups by the number of unknown parameters: the first one with 4 parameters $[3,4]$ and the second one with up to 10 unknown parameters [1] providing a good agreement of observations and calculations in several wavelengths. However, they are complicated by analysing of the colorindex $\mathrm{C}(\alpha)$ dependence and photometric contrast of details with phase $\mathrm{K}(\alpha)$ and on the disk $(\mu \mathrm{o}=\cos$ i). We have got good agreement between observed and calculated values of $\mathrm{C}(\alpha)=\mathrm{U}(\alpha)-\mathrm{I}(\alpha)$, $\mathrm{K}(\alpha), \mathrm{K}(m u \mathrm{o})$ for Moon and Mars with a minimum number of unknown parameters [4]. We used an empirical dependence of single scattering albedo $(\omega)$ and particle semi-transparency $(æ): æ=$ $(1-\omega)$ n. Assuming that $\left.\left[\chi\left(0^{\circ}\right) / \chi\left(5^{\circ}\right)\right]=\chi\left(5^{\circ}\right) / \chi\left(0^{\circ}\right)\right]$, where $\chi(\alpha)$ is scattering function, using the phase dependence of brightness and opposition effect in a single wavelength, we have defined $\omega, \chi(\alpha), \mathrm{g}$ (particle packing factor), and the first term expansion of $\chi(\alpha)$ in a series of Legendre polynomials $\mathrm{x} 1$. Good agreement between calculated and observed data of $\mathrm{C}(\alpha)=\mathrm{U}(\alpha)-\mathrm{I}(\alpha)$ for the light and dark parts of the lunar surface and the integral disk reached at $\mathrm{n} \approx 0,25, \mathrm{~g}=$ 0,4 (porosity 0,91 ), $\mathrm{x} 1=-0,93, \omega=0,137$ at $\lambda=359 \mathrm{~nm}$ and 0,394 at $\lambda=1064 \mathrm{~nm}$; , for Mars with $\mathrm{n} \approx 0,25, \mathrm{~g}=0,6$ (porosity 0,84 ), $\mathrm{x} 1 \approx 0, \omega=0,210$ at $\lambda=359 \mathrm{~nm}$ and $\omega=0,784$ at $\lambda=$ $730 \mathrm{~nm}$.

1. Bowell E., Hapke B., Domingue D., Lumme K., et al. Applications of photometric models to asteroids, in Asteroids II. Tucson: Univ. Arizona Press. p.524-556. (1989)

2. Hapke B. A theoretical function for the lunar surface, J.Geophys.Res. 68, No.15., 45714586(1963).

3. Irwine W. M., The shadowing effect in diffuse reflection, J.Geophys.Res. 71,No.12, 29312937(1966).

4. Morozhenko A. V., Yanovitskij E.G. ,An optical model of the Martian surface in the visible region of spectrum, Astronomy Reports 48, No.4, 795-809(1971).
\end{abstract}

